Article

\title{
Turbulent Flow Field around Horizontal Cylinders with Scour Hole
}

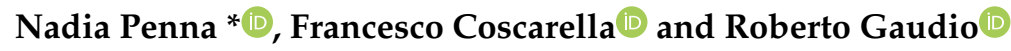 \\ Dipartimento di Ingegneria Civile, Università della Calabria, Via Pietro Bucci, 87036 Arcavacata, Rende CS, Italy; \\ francesco.coscarella@unical.it (F.C.); gaudio@unical.it (R.G.) \\ * Correspondence: nadia.penna@unical.it; Tel.: +39-0984-496-553
}

Received: 21 November 2019; Accepted: 31 December 2019; Published: 2 January 2020

\begin{abstract}
This study presents the results of an experimental investigation on the flow-structure interactions at scoured horizontal cylinders, varying the gap between the cylinder and the bed surface. A 2D Particle Image Velocimetry (PIV) system was used to measure the flow field in a vertical plane at the end of the scouring process. Instantaneous and ensemble-averaged velocity and vorticity fields, viscous and Reynolds stresses, and ensemble-averaged turbulence indicators were calculated. Longitudinal bed profiles were measured at the equilibrium. The results revealed that suspended and laid on cylinders behave differently from half-buried cylinders if subjected to the same hydraulic conditions. In the latter case, vortex shedding downstream of the cylinder is suppressed by the presence of the bed surface that causes an asymmetry in the development of the vortices. This implies that strong turbulent mixing processes occur downstream of the uncovered cylinders, whereas in the case of half-buried cylinders they are confined within the scour hole.
\end{abstract}

Keywords: horizontal cylinder; turbulence structures; scour

\section{Introduction}

Although flow around a cylinder is one of the classical subjects of fluid dynamics, few investigations have focused on the analysis of the turbulence structures of a steady flow at scoured horizontal cylinders. This topic is relevant in the hydraulic field because it is encountered in many engineering applications, such as pipelines suspended, laid on or half-buried installed across mobile riverbeds, where a small depth-to-diameter ratio is most relevant and scouring occurs under unidirectional current [1]. In all these cases, the 3D flow field is extremely complicated due to the separation and the creation of multiple vortices. However, the complexity is further exaggerated owing to the dynamic interaction between the flow and the movable bed [2]. Erosion may occur around the pipelines, causing a higher gap between it and the bed surface and, therefore, compromising their safety. Several research findings can be found in literatures for estimating the local scour around underwater pipelines under unidirectional current [3]. Some of these studies have shown that the scour depth under unidirectional current is always higher than that under pure wave action or the combined effect of wave and current with the same bottom shear stress [3]. Accurate estimates of the scour depth are important because flow-induced oscillation by wake-vortex shedding may provoke fatigue failure of the pipeline itself [4], which is subjected to additional unsteady forces such as lift and drag.

The first investigation for estimating scour depth at submarine pipeline was conducted by Chao and Hennessy [5], who proposed an analytical method for estimating the maximum scour depth under pure current condition. The use of this method was supported by other authors e.g., [6-8]. The main drawback of the method is the use of a potential flow theory in deriving the solution. In real flow, the fluid is not inviscid, and separation occurs at the rear of the pipe. This phenomenon affects the flow conditions [3]. Later, Kjeldsen et al. [9] proposed an equation that implies that the scour 
depth only depends on flow velocity and pipe diameter, but excludes the effect of flow depth and grain size. Bijker and Leeuwestein [10] stated that the scour depth depends on the undisturbed flow velocity, pipe diameter, flow depth, height of pipe above bed level, and grain size. They stated that the principal cause of erosion is a local increase in transport capacity of the water passing a pipeline, while deposition occurs where this capacity decreases [3]. Ibrahim and Nalluri [11] proposed two empirical equations relating the scour depths to flow parameters for both clear-water and live-bed conditions. The equations were derived purely from curve fitting technique. Furthermore, they stated that the grain size has no influence on the scour depth, apart from the indirect influence on the value of the critical velocity. Hansen et al. [12] obtained a relationship between the bed velocity in the scour hole and the two geometric quantities $e / D$ and $d_{s} / D$, where $e$ is the gap between the underside of the cylinder and the original bed level, $D$ is the cylinder diameter and $d_{s}$ the scour depth. They stated that the flume width would also influence this relationship. Mao [13] examined the scour profiles below pipelines under different flow velocities and observed that, for $d_{S} / D<1 d_{s}$, is a weak function of the flow Shields parameter. He also identified two cases of the scour process: (1) jet period, which decides the maximum scour depth; (2) wake period, which decides the location of maximum scour depth. Maza [14] proposed a graphical solution for the estimation of $d_{S}$ that is a function of the initial gap-pipe diameter ratio and the flow Froude number, while Moncada and Aguirre [15] gave an empirical equation of $d_{s}$ assuming a similar functional representation used by Maza [14]. Chiew [16] identified that piping plays a dominant role in initiating scour at submarine pipelines. Later, Chiew [3] proposed an empirical function relating the flow depth ratio, $h / D$, with the gap-flow rate ratio, which can be used to determine the amount of gap flow through the scour hole at equilibrium conditions. Li and Cheng [17] used the finite difference method to solve the Laplace equation of velocity potential and a boundary adjustment technique to calculate the scour profiles below pipelines, while Brørs [18] used the finite element method to simulate the scour profiles below pipelines. Dey and Singh [4] examined their experimental results to describe the influence of various parameters on the equilibrium scour depth, that is flow depth, sediment gradation, different shaped cross-sections of pipes. Lately, Mohr et al. [19] related the rate of scour beneath a pipeline to the fundamental erosion properties of the sediment, namely the transport rate along the bed and the true erosion rate of the sediment. These arguments lead to two new empirical formulas that may be used to predict the time scale of the scour process beneath subsea pipelines. Note that these previous researches concentrate on soil scour around fixed pipelines. More recently, Gao et al. [20] simulated experimentally the current-induced sand scour around a vibrating pipeline to further investigate the mechanism of the coupling effects between pipe vibration and sand scour.

At the same time, several studies have been carried out both numerically and experimentally on the flow field analysis considering a flat bed. A state-of-art review of the research on the cylinder-bed surface interactions exposed to currents was conducted by Fredsøe [1]. For example, Bearman and Zdravkovich [21] carried out an experimental study on the flow around a cylinder lying horizontally at various elevation above a plane bed surface. They demonstrated that regular vortex shedding was suppressed for all gaps less than about $0.3 D$. For gaps greater than $0.3 D$, the Strouhal number, that is the ratio between inertial forces due to the unsteadiness of the flow and expresses the oscillating flow mechanisms, was found to be remarkably constant and the only influence of the plate on vortex shedding was to make it a more highly tuned process as the gap was reduced. Later Zdravkovich [22] studied in detail the flow separation from a flat plate induced by a circular cylinder. He demonstrated that when the cylinder was placed above the bed surface, the downstream separation region contained two counter-rotating vortices separated by stagnant fluid. However, no regular vortex shedding was observed in this configuration, whereas he reported that in the case of turbulent boundary layer vortex shedding occurred for a gap of $0.2 D$ and for the laminar boundary layer at a gap of $0.3 D$. Lei et al. [23] analyzed the hydrodynamic forces and vortex shedding of a cylinder at different locations in the boundary layer. They proposed a quantitative method for identifying the vortex shedding suppression point. Their observations showed that the vortex shedding is suppressed at a gap of about $0.2-0.3 D$, 
depending on the thickness of the boundary layer. This critical gap decreases as the thickness of the boundary layer increases. Price et al. [24] performed visualization studies on the flow-cylinder interactions in the boundary layer. Specifically, they distinguished four distinct regions: (i) for gaps < $0.125 D$, the gap flow is suppressed or extremely weak, and separation of the boundary layer occurs both upstream and downstream of the cylinder. Although there is no regular vortex shedding, there is a periodicity associated with the outer shear-layer; (ii) in the region between $0.125 D$ and $0.5 D$, the flow is very similar to that for very small gaps, except that there is a pronounced pairing between the inner shear-layer shed from the cylinder and the wall boundary layer; (iii) the region between $0.5 \mathrm{D}$ and $0.75 \mathrm{D}$ is characterized by the onset of vortex shedding from the cylinder; (iv) for the fourth region, with a gap greater than $D$, there is no separation of the wall boundary layer, either upstream to or downstream of the cylinder. However, downstream of the obstacle, alternate vortex shedding from the cylinder affects the wall boundary layer. Hatipoglu and Avci [25] studied experimentally and numerically the flow around a horizontal cylinder mounted and partially buried, showing that the lengths of the separation regions near the upstream and downstream of the cylinder decreased with the increasing burial ratio. More recently, Akoz et al. [26] studied quantitatively the flow characteristics of the circular cylinder laid on a fixed surface, by using the Particle Image Velocimetry (PIV) technique. The main purpose was to reveal the mechanisms of vortical flow structures that are mostly responsible for scour and burial processes. They demonstrated that the intersection of the bed surface and cylinder enhances the burial mechanisms hydrodynamically even in wake flow regions. Furthermore, it was shown that the wake flow region is shortened in size in the longitudinal direction as a function of the Reynolds number. More recently, Arslan et al. [27] studied for four different submergence ratios the 3D unsteady flow around a rectangular cylinder with the large eddy simulation (LES) turbulence model. To conduct the analysis, they used the experimental data obtained by Malavasi and Guadagnini [28]. As a result, they characterized the behavior of vortex structures generated by separated flow and the hydrodynamic forces acting on the semi-submerged structure.

Few are the studies in which the turbulence flow structures are analyzed focusing in the neighborhood of the cylinder considering a mobile bed. The first studies on this topic were those of Kjeldsen et al. [9] and Mao [13], who examined the flow around a pipe placed over a scour hole, Jensen et al. [29] investigated experimentally the flow around a pipeline placed initially on a flat bed at five characteristic stages of the scour process in currents. They found that the mean flow field and turbulence around and the force on a pipeline undergo considerable changes, as the scour below the pipeline develops in time and space. Moreover, vortex shedding comes into existence at early stages of scour process, first in a somewhat premature form caused by the close proximity of the dune formed downstream the pipe as a result of deposition of scoured material. As the dune moves away from the pipe, the vortex shedding gradually reaches a stage which resembles the shedding process of a free cylinder. Starting from this experimental campaign, Smith and Foster [30] examined the flow physics around the pipeline (considering also the bed scouring phenomenon) using numerical modelling. They compared the mean horizontal and vertical velocities and the wake characteristics measured by Jensen et al. [29] to those obtained by applying a computational fluid dynamics (CFD) model (Flow3D) using both a two-equation $k-\varepsilon$ model and a Smagorinsky LES turbulence closure scheme for five stages of the scour process.

Thus, the main purpose of the study was to identify the flow structures in shallow water condition developed once the bed scour reached the equilibrium, varying the gap between the cylinder and the bed surface. Specifically, three different conditions were reproduced in a laboratory flume: a suspended cylinder, a laid on cylinder and a half-buried cylinder. The analysis was focused on the velocity measurements in correspondence of the horizontal cylinder and on the determination of the instantaneous and ensemble-averaged velocity fields, the instantaneous and ensemble-averaged vorticity fields, viscous and Reynolds stresses, and the ensemble-averaged turbulence indicators. In addition, the equilibrium longitudinal bed profiles were discussed in order to better comprehend the effect induced by the flow-structure interactions. 


\section{Experimental Set-Up and Procedure}

The experimental campaign was performed at the Laboratorio "Grandi Modelli Idraulici" (GMI, Università della Calabria, Italy). A recirculating flow channel $(9.6 \mathrm{~m}$ long, $0.485 \mathrm{~m}$ wide, $0.5 \mathrm{~m}$ deep) was used in this study. The flume side walls were made of glass in order to visualize the flow. The inlet of the flume comprised of a stilling tank, an uphill slipway, and honeycombs (having a diameter of $10 \mathrm{~mm}$ ) to dampen the flow disturbances at the entry. The test section was located at $7.33 \mathrm{~m}$ downstream of the flume entrance and it was $0.165 \mathrm{~m}$ long. The flow depth was regulated by a downstream tailgate. To collect the outflow, a tank equipped with a calibrated Thomson weir to measure the flow discharge was attached downstream of the tailgate.

The bed was constituted by very coarse sand having a median sediment size $d_{50}$ of $1.53 \mathrm{~mm}$ (0.06 $\mathrm{mm}<d<2 \mathrm{~mm}$, where $d$ is the size of sediments) and geometric standard deviation $\sigma_{g}$ [ $=\left(d_{84} / d_{16}\right)^{0.5}$ ] of 1.24 , where $d_{16}$ and $d_{84}$ are the $16 \%$ and $84 \%$ (by weight) finer sizes of sediments, respectively. The sediment density was $\rho_{s}=2680 \mathrm{~kg} / \mathrm{m}^{3}$. To prepare the bed, sediments were initially spread within the flume and screeded to create a bed with a longitudinal slope $S_{0}$ of $0.1 \%$.

A horizontal cylinder of $30 \mathrm{~mm}$ in diameter made of Plexiglas was set up at the center of the test section. The cylinder was fixed to the flume walls and kept normal to the flow direction. Three different gaps, respectively $e_{1}, e_{2}$ and $e_{3}$, between the cylinder and the bed surface were considered, as represented in Figure 1 and reported in Table 1: (i) suspended cylinder; (ii) cylinder laid on the bed; (iii) partially buried cylinder. To ensure direct comparisons of the results, the bed surface was leveled at the start of each experiment.

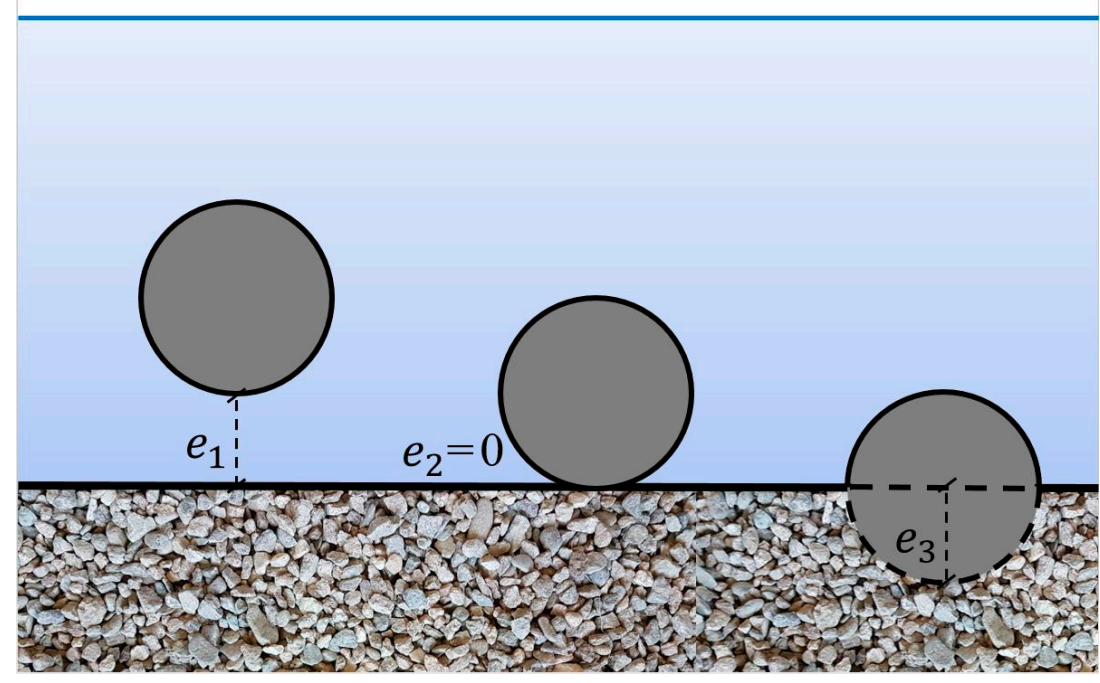

Figure 1. Schematic representation of the geometrical conditions of the experimental runs, where $e_{i}$ $(i=1,2,3)$ is the gap between the lower edge of the cylinder and the bed surface.

Table 1. Geometric and hydraulic parameters of the experimental runs.

\begin{tabular}{cccc}
\hline Parameter (Units) & Run 1 & Run 2 & Run 3 \\
\hline$e_{i}(\mathrm{~m})$ & 0.015 & 0 & -0.015 \\
$h(\mathrm{~m})$ & 0.073 & 0.073 & 0.076 \\
$Q\left(\mathrm{~m}^{3} / \mathrm{s}\right)$ & 0.010 & 0.010 & 0.010 \\
$U(\mathrm{~m} / \mathrm{s})$ & 0.28 & 0.28 & 0.27 \\
$U_{c}(\mathrm{~m} / \mathrm{s})$ & 0.37 & 0.37 & 0.37 \\
$u_{*}(\mathrm{~m} / \mathrm{s})$ & 0.026 & 0.026 & 0.025 \\
$\operatorname{Re}$ & $7.9 \times 10^{4}$ & $7.9 \times 10^{4}$ & $7.9 \times 10^{4}$ \\
$R e_{c}$ & $8.1 \times 10^{3}$ & $8.1 \times 10^{3}$ & $7.8 \times 10^{3}$ \\
$R e_{*}$ & 85 & 85 & 82 \\
$F r$ & 0.33 & 0.33 & 0.31 \\
\hline
\end{tabular}


The runs were carried out under the same hydraulic conditions. Specifically, the initial flow depth $h$ was about $0.074 \mathrm{~m}$, as measured immediately upstream to the cylinder from the sediment crest. Therefore, the aspect ratio $B / h$ was greater than 5 ( $B$ being the flume width) and the effect of the sidewalls is negligible [31] in our experimental set-up. However, the ratio $h / D$ was kept constant and equal to 2.5. Thus, being $h / D<5$ [4], the shallowness effect is present in all the runs and, therefore, the resulting scouring process is due to the cylinder-bed surface interactions at different gaps in shallow water condition. The threshold flow velocity, $U_{c}$, was determined using Neill's empirical formula [32] and was equal to $0.37 \mathrm{~m} / \mathrm{s}$, higher than the average flow velocity $U=Q /(B h) \approx 0.28 \mathrm{~m} / \mathrm{s}, Q$ being the flow discharge. This indicates a clear-water condition. The flow Reynolds number $\operatorname{Re}(=4 \mathrm{Uh} / \mathrm{v}$, where $v=1.04 \times 10^{-6} \mathrm{~m}^{2} / \mathrm{s}$ at $18.4^{\circ} \mathrm{C}$ is the kinematic water viscosity), the flow Froude number $\mathrm{Fr}\left[=\mathrm{U} /(\mathrm{gh})^{0.5}\right.$, where $g$ is the gravitational acceleration], the cylinder Reynolds number $\operatorname{Re}_{\mathcal{c}}(=U D / v$, where $D$ is the cylinder diameter) and the other hydraulic parameters are listed in Table 1 for each experimental run. Specifically, upstream of the cylinder (where the flow was not affected), the shear velocity $u *$ was estimated by extending the Reynolds shear stress profile linearly to the maximum gravel crest as $\left.\left(-\overline{u^{\prime} w^{\prime}}\right)^{0.5}\right|_{z=z_{c}}$ (where $u^{\prime}$ and $w^{\prime}$ are the temporal velocity fluctuations in the streamwise and vertical directions, respectively, and $z_{\mathcal{c}}$ is the maximum gravel crest elevation). Hence, the Reynolds number of the sediments $R e *$ was calculated as $u * \varepsilon / v$, where $\varepsilon$ is the equivalent sand roughness height $\approx 2 d_{50}$ [33].

During all the experimental runs bed scouring occurred. It was found that the equilibrium scour depth was reached within $24 \mathrm{~h}$ for all the three experimental runs. This is in line with the findings of Chiew [3]. Dey and Singh [4] demonstrated that the time to reach the equilibrium scour below a pipeline is shorter than that at an abutment, since it is due to strong pressurized flow and not to primary or horseshoe vortex. Also, Mao [13] observed equilibrium scour below a cylinder in just over $3 \mathrm{~h}$.

A 2D PIV system manufactured by TSI was used to measure the flow field. It consisted of a 12 bit CCD camera (Nikon, city, country, 50 mm F1.8 lens, $2048 \times 2048$ pixel $^{2}$ resolution, $15.2 \times 15.2 \mathrm{~mm}^{2}$ sensor size) and a double pulse Nd:YAG laser with a frame rate of $15 \mathrm{~Hz}$ and a pulse energy of $200 \mathrm{~mJ}$ at a wavelength of $532 \mathrm{~mm}$. Titanium dioxide powder, having a diameter of $3 \mu \mathrm{m}$ and a mass density of $4.26 \mathrm{~kg} / \mathrm{m}^{3}$, was used as a tracer during flow measurements. The test section was illuminated with the laser to capture the movement of the tracer particles through the camera placed parallel to the laser sheet. The flow measurements were taken in correspondence of the horizontal cylinder. In order to measure the flow field, 3000 pairs of images were captured over a period of about $200 \mathrm{~s}$. The inter-frame time between two laser pulses was set equal to $1400 \mu \mathrm{s}$, which means that, considering $U \approx 0.28 \mathrm{~m} / \mathrm{s}$, we were able to measure only eddies greater than $0.39 \mathrm{~mm}$. The actual size of the eddy is imposed by the spatial resolution of the PIV measurements [34]. The field of view was $165 \times 165 \mathrm{~mm}^{2}$ with an interrogation area of $32 \times 32 \mathrm{pixel}^{2}$. A $50 \%$ overlap of the interrogation areas was employed to increase the spatial resolution of the measurement [35] to about $1.3 \mathrm{~mm}$ (which corresponds to $12.4 \mathrm{pixel} / \mathrm{mm}$ ). The Insight 4G-2DTR software was used during the acquisition phase and to process the resulting data.

The precision in the flow velocity measurements with a PIV system depends to a great extent on the errors introduced by the sub-pixel estimator in the cross-correlation. This is known as "peak-locking" and is a bias error in the PIV that occurs when the particle images are too small, causing the particle image displacement to be biased toward integer value. The error is estimated to be $10 \%$ of the particle image diameter, which is the diameter in pixels of the particle as seen through the camera [36]. The mean particle image diameter in the present case is about 1 pixel, and a typical displacement between the cross-correlation image pairs is 5 pixels in the main flow direction. Therefore, the estimated random error of the measured velocity vector in each interrogation area is about $2 \%$ for the streamwise velocity component.

However, as a priori method, in order to reduce peak-locking, through a trial and error procedure we set an aperture number $f \#$ equal to 11 , in order to ensure that all the tracer particles in the light sheet (having a thickness of $2 \mathrm{~mm}$ ) were in focus. Nevertheless, following the procedure described in Padhi et al. [34], we used also and a posteriori method pre-processing all the images by using a filter (already available in the Insight 4G-2DTR software), which optimized the particle image diameter with respect to the peak estimator, in order to improve the signal-to-noise ratio. 
The flow was stopped at the end of the measurement phase and, subsequently, the flume was slowly emptied without any disturbance for the bed scour by using a bottom outlet located $1 \mathrm{~m}$ downstream of the test section. For each run, the bed surface was acquired with the photogrammetry technique. Photogrammetry is used in different fields such as topographic mapping, architecture, engineering, cultural heritage and geology e.g., [37-39]. Following the procedure described in Penna et al. [40], a Nikon D5200 camera was used, equipped with a Nikkor $18-55 \mathrm{~mm} \mathrm{f} / 3.5-5.6 \mathrm{G}$ VR lens. The resulting 3D point cloud was at first transformed into an unstructured triangular mesh by using the software PhotoScan (Agisoft, St. Petersburg, Russia). Then a structured grid was extracted using the commercial software Rhinoceros (McNeel \& Associates, Seattle, WA, USA), with a spatial resolution $\delta l=5 \mathrm{~mm}$ in both the streamwise and spanwise directions.

\section{Results and Discussion}

\subsection{Longitudinal Bed Profiles}

The centerline longitudinal bed profiles at equilibrium, for each experimental run, are shown in Figure 2. Here, the origin of the $x$-axis (streamwise direction) is set in correspondence of the cylinder center, whereas the $z$-axis indicates the vertical direction. Specifically, the horizontal and vertical axes were made dimensionless by dividing them by the cylinder diameter. Furthermore, $z / D=0$ is the bed surface at the start of each experiment. These longitudinal profiles were extracted from the bed surface models derived from the photogrammetry technique.

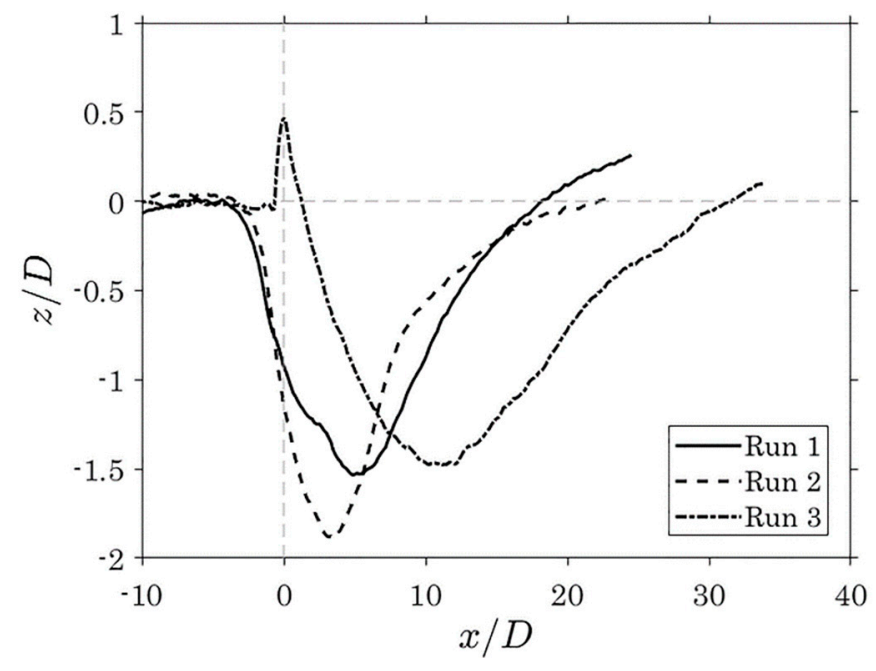

Figure 2. Centerline longitudinal bed profiles at equilibrium.

The data clearly highlight how the gap between the cylinder and the bed surface influences the scour formation and, thus, the bed profile. A steady flow that impacts on a cylinder laid on the bed causes a deeper scour hole than in the case in which the cylinder is suspended. Specifically, it was $1.5 \mathrm{D}$ $=4.6 \mathrm{~cm}$ and $1.9 \mathrm{D}=5.7 \mathrm{~cm}$ for Run 1 and Run 2 , respectively. This means that the gap in Run 1 allows the flow to pass with less disturbance to the sand bed. It is also evident that the maximum equilibrium scour depth $d_{s}$ occurs closer to the cylinder in the second case than in Run 1 . The distance between the center of the cylinder and the maximum equilibrium scour depth, $x_{s}$, is $5 D=15 \mathrm{~cm}$ for Run 1 and $3.5 D$ $=10.5 \mathrm{~cm}$ for Run 2 . The behavior can be explained by analyzing the vortex system induced by the fluid-structure interaction, which is described in the following sections. Furthermore, it is possible to note that the resulting scour hole involves the area upstream to and beneath the cylinder, owing to a particular process also known as tunnel erosion [41], that is ascribed to seepage processes [2,42] and occurs when the ratio between the flow depth and the cylinder diameter is less than 3.5 [16]. The vortices due to the obstacle led to instabilities to the particles, moving them away. The consequent erosion process is due to the increased velocity underneath the cylinder. 
A different behavior can be noted considering Run 3 in which the cylinder is half-buried: tunnel erosion does not occur and the scour hole develops downstream of the cylinder itself. Hence, in this case, the shape of the bed profile is comparable to that formed in the presence of a bed sill subjected to a steady flow. This will be further explained analyzing the flow field around the cylinder in the following sections. Interestingly, even if $d_{s}$ is the smallest value $\left(d_{s}=1.5 D=4.4 \mathrm{~cm}\right)$ if compared to the other two cases, the scour length $l_{s}$ is about $0.3 D=0.9 \mathrm{~m}$ and, therefore, the scouring process affects a larger amount of sediments than in Run 1 and Run 2, for which it is almost $0.22 D=0.65 \mathrm{~m}$. Note that the small hump visible in Figure 2 at $x / D=0$ is the profile of the cylinder itself.

The obtained bed profile at equilibrium for $e=0$ (Run 2) was compared with the experimental data of Chiew [3], Gao et al. [20] and Dey and Singh [4]. To better understand the different behavior that can be observed in Figure 3, Table 2 shows the experimental conditions adopted for each run. The bed profiles of Gao et al. [20] and Dey and Singh [4] were determined in deep-water condition $(h / D>5)$, whereas those related to the studies conducted by Chiew [3] and of the present work were in shallow-water condition $(h / D<5)$. Therefore, it is easy to note that for shallow-water condition a deeper and longer scour hole is formed, leaving aside for the moment considerations about the other parameters involved. Furthermore, in the case of deep-water condition the scour hole develops to great extent below the cylinder, whereas for shallow-water the maximum scour depth is reached downstream of it. By comparing the bed profile of Run 2 and that of Gao et al. [20], which are characterized by similar cylinder diameter and flow velocity, the higher water depth of Gao et al. [20] produced a maximum scour depth of about $1.8 \mathrm{~cm}$, whereas that obtained in the present study was about $5.7 \mathrm{~cm}$, although $d_{50}$ was 4 times less than $1.53 \mathrm{~mm}$ of Run 2 . However, it must be pointed out that also the considered equilibrium time $\left(t_{e}\right)$ can influence the observed discrepancies between the bed profiles. Based on results obtained from Chiew [3], only $50-70 \%$ of the equilibrium scour depth is reached in three to four hours of testing. Finally, by comparing the bed profile of Run 2 and that of Dey and Singh [4], which are characterized by a similar sediment size, it is possible to note that the maximum scour depth is of the same order, despite the fact that $D$ and $U$ are higher than those of the present study. This can again be ascribed to both the water depth and also to the equilibrium time.

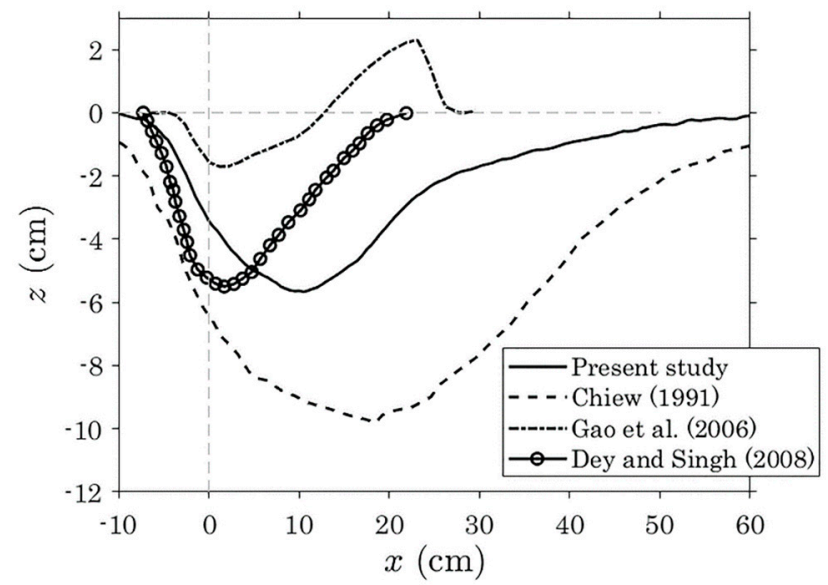

Figure 3. Comparison between centerline longitudinal scour profiles around a horizontal cylinder with $e=0$.

Table 2. Geometric and hydraulic parameters of the literature experimental runs for $e=0$.

\begin{tabular}{cccccc}
\hline & $\boldsymbol{D} \mathbf{( c m )}$ & $\boldsymbol{d}_{\mathbf{5 0}} \mathbf{( \mathbf { m m } )}$ & $\boldsymbol{h} \mathbf{( \mathbf { c m } )}$ & $\boldsymbol{U} \mathbf{( m / s )}$ & $\boldsymbol{t}_{\boldsymbol{e}}(\mathbf{h})$ \\
\hline Present study & 3 & 1.53 & 7.3 & 0.280 & 24 \\
Chiew (1991) [3] & $3.2 \div 6.3$ & $0.33 \div 1.70$ & $5 \div 18$ & - & $>24$ \\
Gao et al. (2006) [20] & 3.2 & 0.38 & 40 & 0.255 & 4 \\
Dey and Singh (2008) [4] & 4 & 1.86 & 20 & 0.497 & 12 \\
\hline
\end{tabular}




\subsection{Instantaneous and Ensemble-Averaged Velocity Fields}

A sequence of four consecutive instantaneous flow fields at different times $t$ for all the experimental runs are shown in Figure 4. The velocity has a magnitude $|\mathbf{u}|=\left(u^{2}+w^{2}\right)^{0.5}$, where $u$ and $w$ are the instantaneous streamwise and vertical velocity components, respectively. The velocity was made dimensionless by dividing it by $U$. The origin of the $x$-axis refers to the start of the test section acquired with the PIV system. Both the axes were made dimensionless by dividing by $D$. Furthermore, Figure 4 shows the streamlines for each velocity field. Note that invalid vectors were removed from the instantaneous velocity fields (blank areas in the colormaps), as well as those below and along the edge of the cylinder since they corresponded to an area poorly illuminated by the laser. Vectors identified as spurious were replaced by the ensemble-averaged values when computing the average over time.

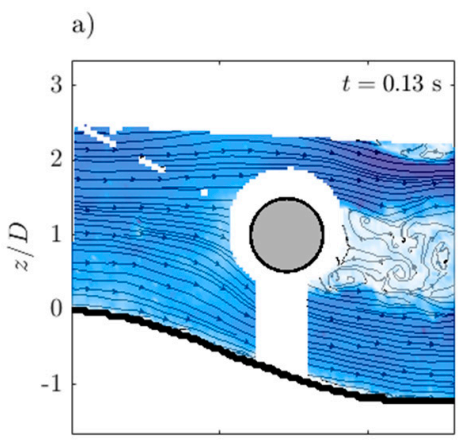

b)
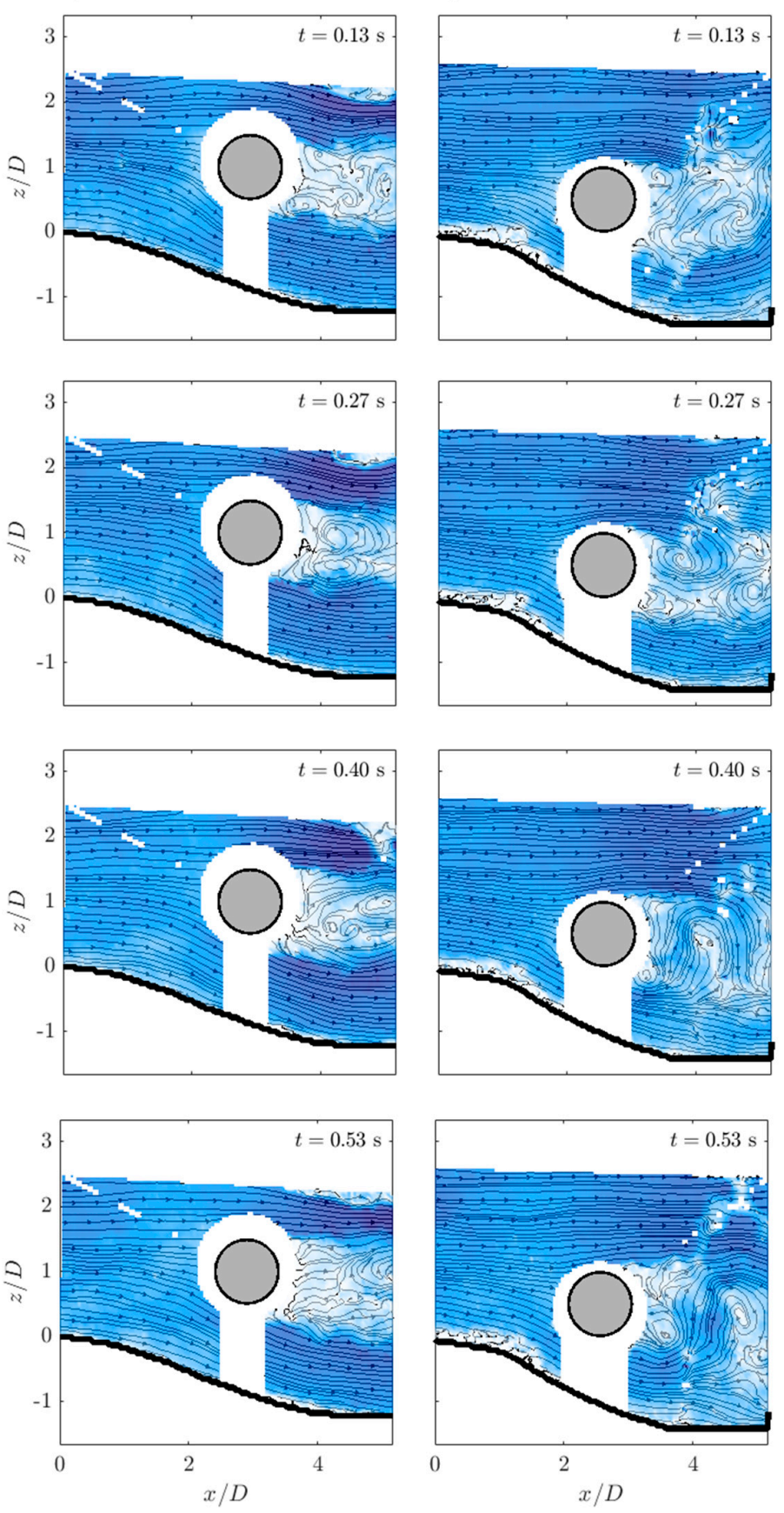

c)
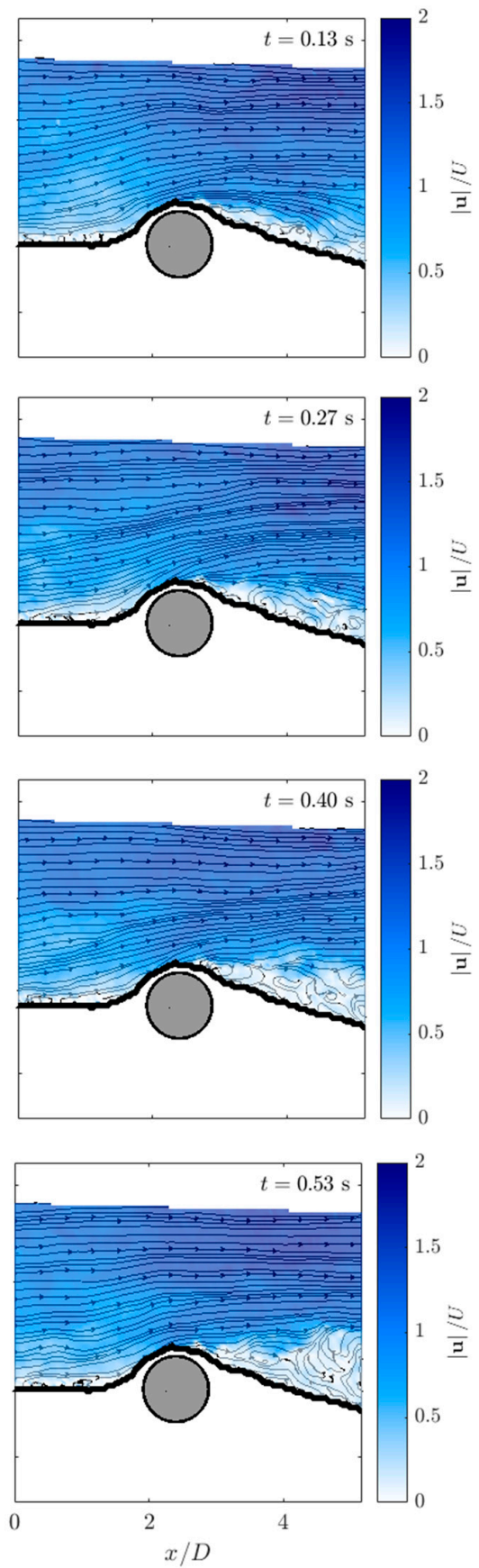

Figure 4. Dimensionless instantaneous velocity fields at different times $t$ on a vertical plane in (a) Run 1, (b) Run 2 and (c) Run 3. 
From the analysis of Figure 4, it is evident that upstream to the cylinder, at the beginning of the study area, the flow velocities, in all the three runs, increase with the vertical distance $z$, as usually observed in an open-channel flow, and the streamlines are nearly horizontal. Thus, in both Run 1 and Run 2, the incoming flow approaches the upstream face of the cylinder and causes flow separation. The main flow is divided into two flows: one part is oriented towards the bed surface (this is the main cause of scouring) and the other part is oriented towards the free surface [26], giving birth to two separation zones. Since $300<R e_{c}<3 \times 10^{5}$ (Table 1), the boundary layer over the cylinder surface is laminar. For Run 2 the separation zone at the free-stream side of the cylinder moves upstream with respect to that of Run 1 . This is in agreement with previous findings [26,29,43]. A different behavior occurs for Run 3: the obstruction represented by the cylinder creates an adverse pressure gradient resulting in the separation of flow lines forming a vortex on the upstream front of the cylinder. Separation of flow also takes place at the free-stream side of the cylinder. Reverting to Run 1 and Run 2 , a pair of vortices in the wake of the cylinder is noticeable, causing vortex shedding. The vortices are shed alternately at both sides of the cylinder at a certain frequency. Specifically, following the classification of Sumer and Fredsøe [43], the generated wake is completely turbulent, whereas the vortex-shedding frequency, $f$, can be derived from the Strouhal number:

$$
S t=\frac{f \times D}{U}
$$

The Strouhal number in proximity of a wall may change with respect to the case in which no wall is present. Shedding frequency tends to increase (yet slightly) as the gap ratio decreases [44]. However, the flow field in this study was analyzed at the equilibrium phase, that is when the scouring phenomena was already exhausted. This means that the gap between the cylinder and the bed is $4.27 \mathrm{~cm}$ and $3.43 \mathrm{~cm}$ for Run 1 and Run 2, respectively (Figure 2). Therefore, since the gap ratio $e_{i} / D$ is higher than 1 for Run 1 and Run 2 (1.42 and 1.14, respectively), it is possible to assume that in these cases the Strouhal number in proximity of the wall is equal to the Strouhal number for wall-free cylinder $[44,45]$. Note that the vortex shedding occurs in a region where the scour hole is deeper than that at the cylinder itself $\left(e_{1} / D>1.42\right.$ and $e_{2} / D>1.14$ for Run 1 and Run 2, respectively). Therefore, the wall represented by the mobile bed has no effects on the Strouhal number, even if concave and not flat. Considering that for a smooth circular cylinder $S t$ remains practically constant at the value of 0.2 for $300<R e_{c}<3 \times 10^{5}$ [46], the vortex-shedding frequency can be determined as $S t \times U / D$, thus $1.87 \mathrm{~s}^{-1}$ for Run 1 and Run 2 . This means that vortex shedding occurs about twice per second. Figure 4 helps in visualizing the formation and destruction of the vortex system, from $t=0.13 \mathrm{~s}$ to $0.53 \mathrm{~s}$, with $t=0$ at the beginning of the experimental measurements. The vortex originated from the free-stream side of the cylinder (e.g., Figure $4 \mathrm{~b}$ at $t=0.13 \mathrm{~s}$ ) is strong enough to draw the opposing vortex (at the cylinder wall-side) downstream across the wake region (e.g., Figure $4 \mathrm{~b}$ at $t=0.27 \mathrm{~s}$ ). Note that the streamlines coming from above are oriented in the clockwise direction, while the others in the anti-clockwise direction. The opposite sign will then cut off further supply of vorticity to the upper vortex from its boundary layer [43], and therefore this vortex is shed and the transported downstream by the flow (e.g., Figure $4 \mathrm{~b}$ at $t=0.40 \mathrm{~s}$ ). Thus, a new vortex forms at the free-stream side of the cylinder. However, the lower vortex is now stronger than this new upper vortex and, therefore, this will lead to its shedding (e.g., Figure $4 \mathrm{~b}$ at $t=0.53 \mathrm{~s}$ ). Instead, for Run 3 a reverse roller is formed in the wake region. Vortex shedding is suppressed by the presence of the bed surface that causes an asymmetry in the development of the vortices [43].

To analyze the ensemble-averaged flow field in a spatial flow domain, Figure 5 shows the streamlines and the contours of the velocity having a magnitude $|\overline{\mathbf{u}}|=\left(\bar{u}^{2}+\bar{w}^{2}\right)^{0.5}$, where $\bar{u}$ and $\bar{w}$ are the ensemble-averaged streamwise and vertical velocity components, respectively. The ensemble-averaged velocity was made dimensionless by dividing it by $U$. 
a)

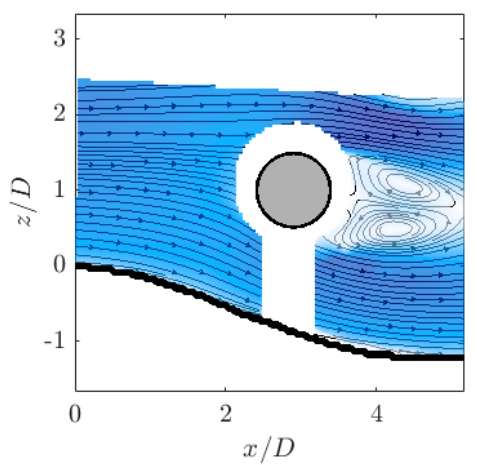

b)

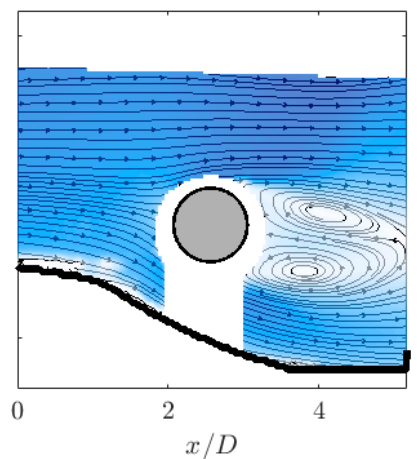

c)

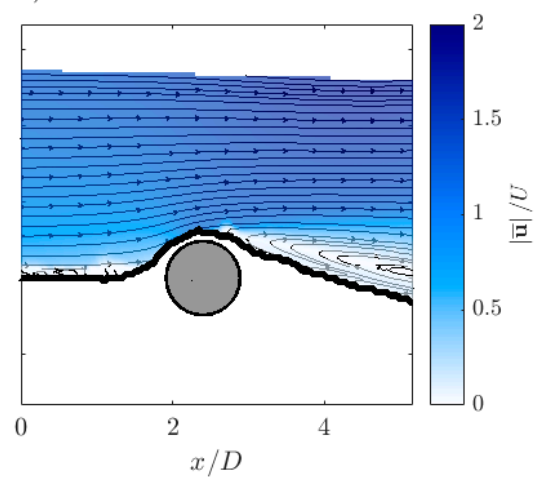

Figure 5. Dimensionless ensemble-averaged velocity fields on a vertical plane in (a) Run 1, (b) Run 2 and (c) Run 3.

The analysis of Figure 5 recalls the separation of the main flow upstream to the cylinder in both Run 1 and Run 2, described on the basis of the instantaneous velocity fields of Figure 4. It is apparent that the increase of the gap between the cylinder and the bed surface (Run 1) causes the formation of two opposite vortices in the wake of the cylinder shorter and more compressed than those of Run 2. This behavior may be attributed to the fact that in Run 1 the cylinder is close to the water surface, pushing down the upper vortex. In the meantime, a greater amount of flow passes below the cylinder and, therefore, tends to expand immediately downstream of it, compressing the vortex system in the wake region. The velocity at the underside of the cylinder is slightly lower than the one at the top side. This is in agreement with the observations of Jensen et al. [29]. The ensemble-averaged velocity field of Run 3, instead, shows the roller vortices upstream to and downstream of the cylinder in the scour hole, as discussed before. This led to a flow acceleration along the water depth above the recirculation zone.

Figure 6 shows the vertical profiles of the ensemble-averaged streamwise flow velocity at different distances upstream to and downstream of the cylinder. Again, it is illustrated how the velocity profiles are not influenced by the horizontal cylinder at the beginning of the area of interest, in all the three experimental runs. For Run 3 only, negative values of $u$ are shown upstream to the cylinder, owing to the presence of the vortex originated from the interaction between the current and the obstacle. Immediately downstream of the cylinder in Run 1 and Run 2, the streamwise flow velocity is negative, indicating a reverse flow. Increasing the distance from the cylinder, it loses intensity and the vertical profiles start recovering the undisturbed upstream condition. However, the velocity profiles are different if we refer to Run 3 , in which the shear layer separates from the cylinder, creating a recirculation zone.

a)

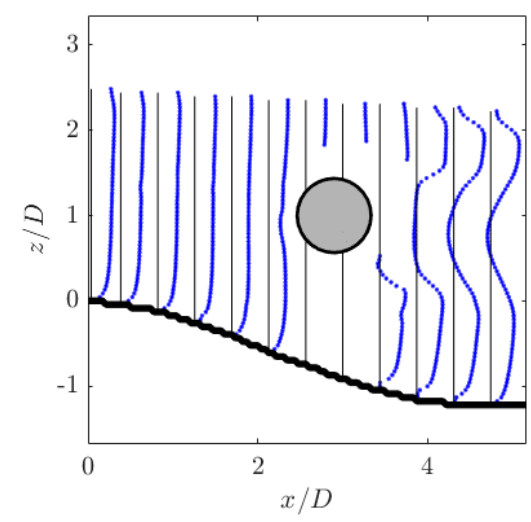

b)

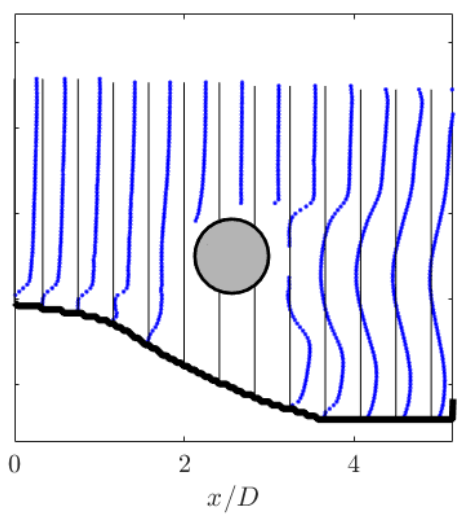

c)

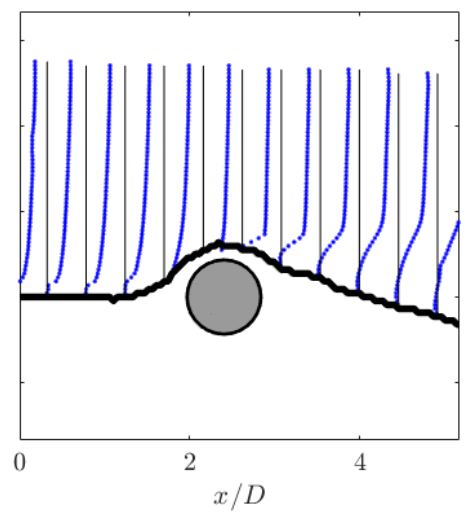

Figure 6. Vertical profiles of the ensemble-averaged streamwise flow velocity at different streamwise distances in (a) Run 1, (b) Run 2 and (c) Run 3. 


\subsection{Instantaneous and Ensemble-Averaged Vorticity Fields}

The contours of dimensionless instantaneous vorticity $\omega_{y} D / U$ are shown in Figure 7 at different times $t$. Here, $\omega_{y}$ is the instantaneous vorticity given by $\partial u / \partial z-\partial w / \partial x$, whose positive and negative values specify clockwise and counterclockwise fluid motions, respectively. Specifically, the counterclockwise fluid motion causes the flow to accelerate, resulting in a downward transport of momentum in the downstream direction, and the clockwise fluid motion causes the flow to decelerate, resulting in an upward transport of momentum in the upstream direction [47].

a)
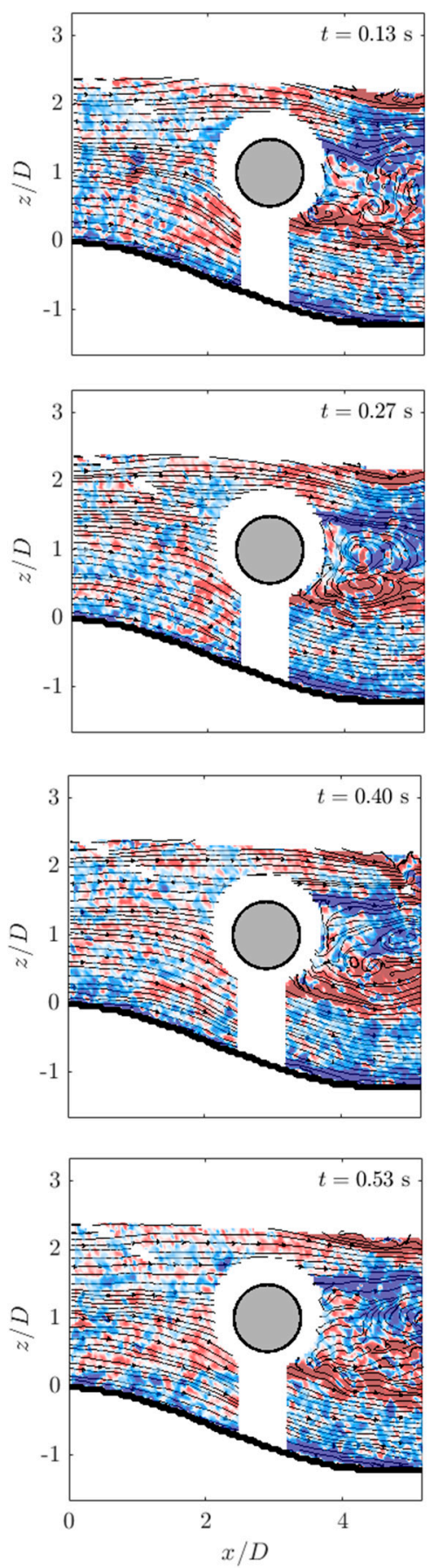

b)
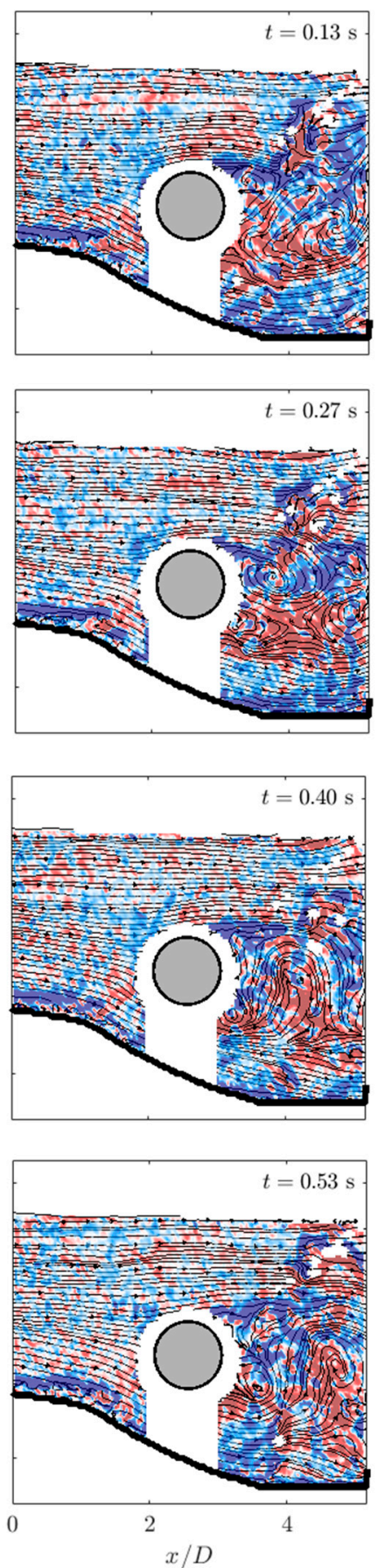

c)
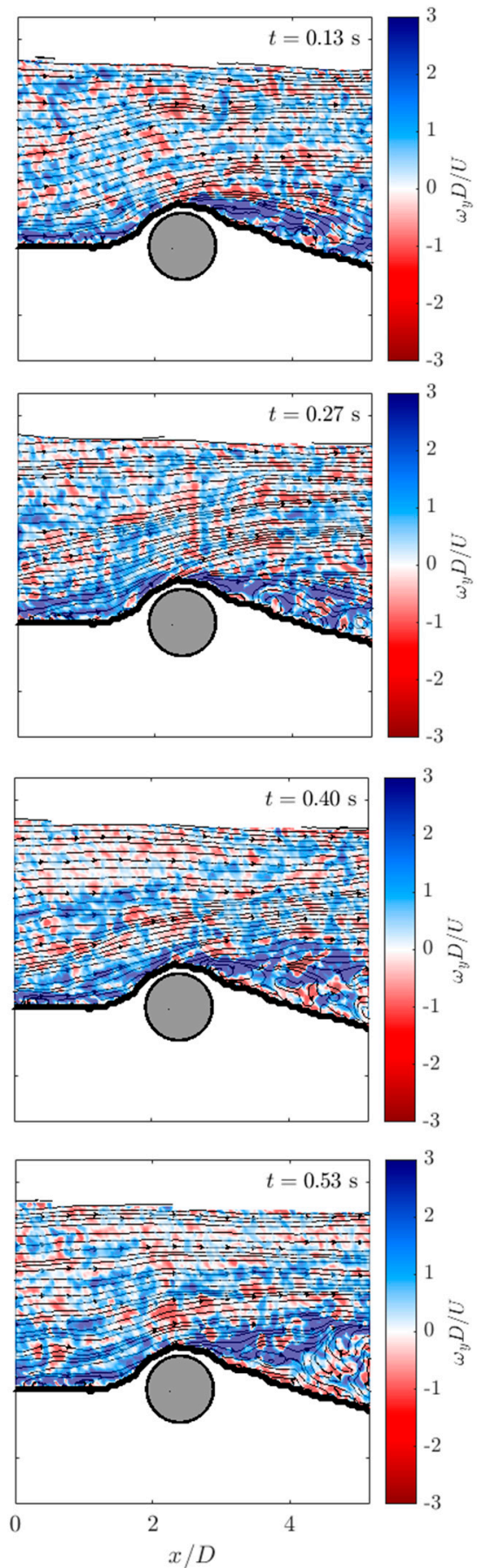

Figure 7. Dimensionless instantaneous vorticity fields at different times $t$ on a vertical plane in (a) Run 1, (b) Run 2 and (c) Run 3. 
From the analysis of Figure 7, the patterns of vorticity show that in the wake region of Run 1 and Run 2 a cluster of vorticity takes place along the shear layers. This is due to the separation induced by a pressure increase along the cylinder surface. The vortex that originates from the separation zone at the free-stream side of the cylinder has a positive sign indicating a clockwise rotation, whereas the vortex from the wall-side has a negative sign with a counterclockwise rotation. These motions are responsible for the production of the Reynolds shear stresses [48]. It is also evident that for Run 2 the steep slope of the scour hole behind the cylinder forces the shear layer originating from the lower edge of the cylinder to bend upwards, thus causing the associated lower vortex to interact with the upper one prematurely, as it was observed by Jensen et al. [29]. As regards to Run 3, the vortex downstream of the cylinder rotates with clockwise direction in the scour hole, creating a recirculation zone with decelerated fluid motion. However, in all the three cases it is found that the vortices do not change their rotational sense with time; therefore, they are recursive with time.

Figure 8 shows the streamlines and the contours of the dimensionless ensemble-averaged vorticity $\bar{\omega}_{y} D / U$, to substantiate the effects illustrated by the instantaneous vorticity patterns. Here, $\bar{\omega}_{y}$ is the ensemble-averaged vorticity given by $\partial \bar{u} / \partial z-\partial \bar{w} / \partial x$. At the upstream end of the investigated area, the vorticity is null along the water depth in all the three experimental runs. However, in the near-bed flow clockwise vortices occur owing to the bed roughness. For Run 1 and Run 2, downstream of the cylinder, in the wake region, vorticity assumes positive values in the upper zone and negative values in the lower part, that is with clockwise and counterclockwise rotations, respectively. Instead, Run 3 shows the clockwise vortex in the scour hole, as previously discussed.

a)

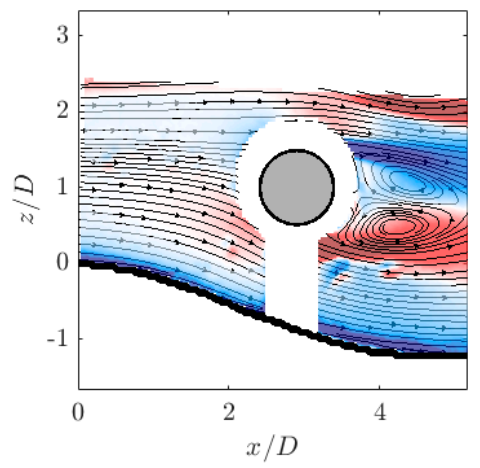

b)

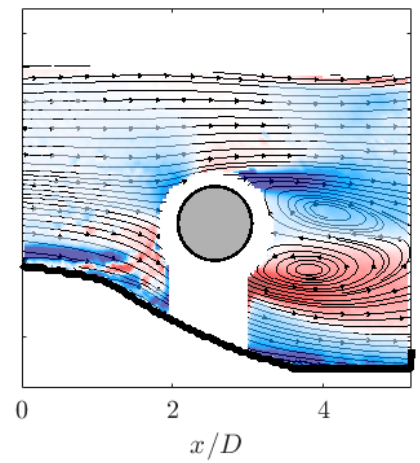

c)

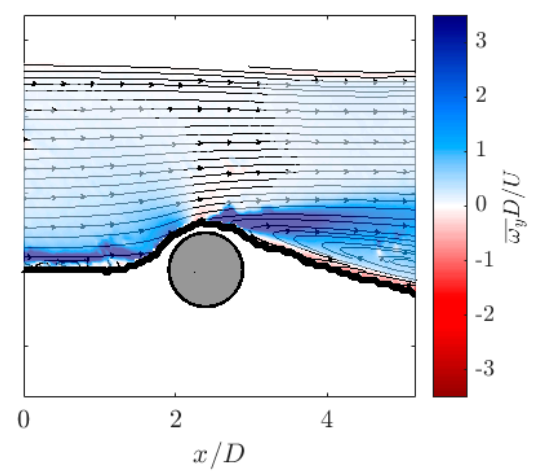

Figure 8. Dimensionless ensemble-averaged vorticity fields on a vertical plane in (a) Run 1, (b) Run 2 and (c) Run 3.

\subsection{Viscous and Reynolds Stresses}

The variations of the dimensionless viscous stresses $\tau_{v}$ in the flow domain, calculated as $(v d \bar{u} / d z) / u_{*}^{2}$ are depicted in Figure 9. Instead, the dimensionless Reynolds shear stresses $\tau_{u w}=-\overline{u^{\prime} w^{\prime}} / u_{*}^{2}$ are shown in Figure 10.

By comparing Figures 9 and 10, it is evident that upstream to the cylinder the viscous stresses are negligible along the water depth and increase in the near-bed flow zone in all the experimental runs. At the same time, $\tau_{u w}$ tends to assume a peak value at a certain distance from the bed surface and then starts decreasing. A different behavior is shown in Run 3, since a small region of negative values of $\tau_{u w}$ is evident close to the bed surface, owing to the small vortex on the upstream front of the cylinder. Considering Run 1 and Run 2, downstream of the cylinder two regions characterized by the maximum positive and negative values of the Reynolds shear stress occur. This suggests strong turbulent mixing process in these areas, indicating a downward transport of momentum in the downstream direction and an upward transport of momentum in the upstream direction, respectively. Close to the cylinder surface, $\tau_{v}$ assumes the highest positive and negative values where the shear stress is almost null. 
As regards Run 3, both $\tau_{v}$ and $\tau_{u w}$ assume their maximum values in the scour hole, which suggests a strong turbulent mixing process that entrains high-momentum fluid into the recirculation region.
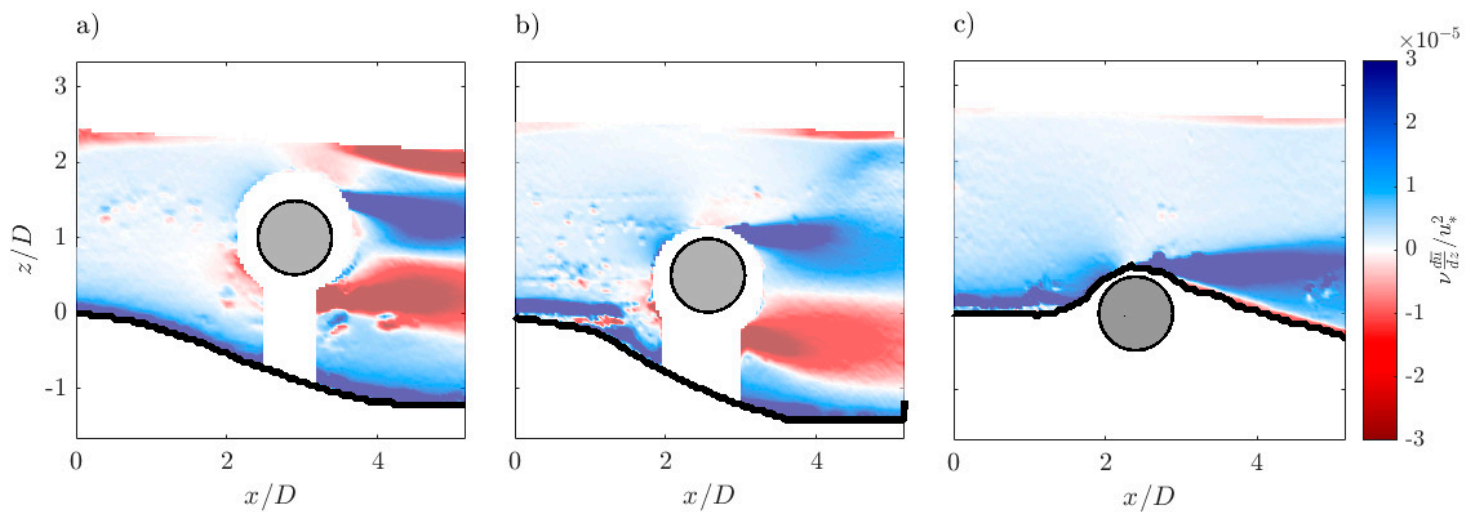

Figure 9. Dimensionless viscous stresses on a vertical plane in (a) Run 1, (b) Run 2 and (c) Run 3.

a)

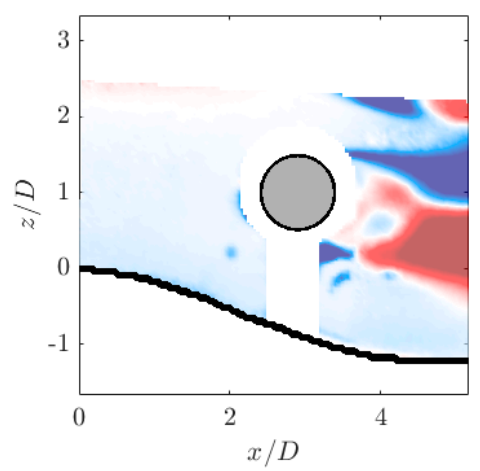

b)

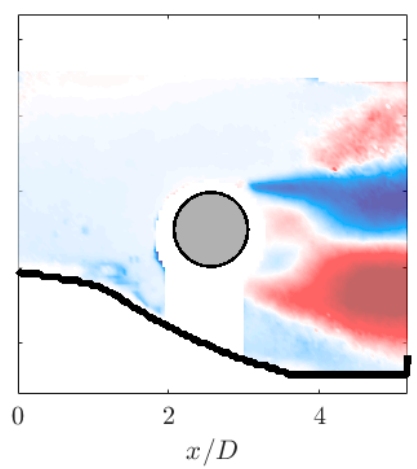

c)

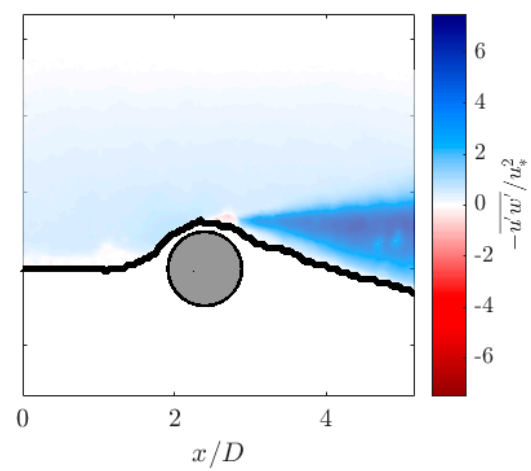

Figure 10. Dimensionless Reynolds shear stresses on a vertical plane in (a) Run 1, (b) Run 2 and (c) Run 3.

Finally, the dimensionless streamwise and vertical Reynolds normal stresses, expressed as $\sigma_{u u}=-\overline{u^{\prime} u^{\prime}} / u_{*}^{2}$ and $\sigma_{w w}=-\overline{w^{\prime} w^{\prime}} / u_{*}^{2}$, respectively, are shown in Figures 11 and 12.

a)

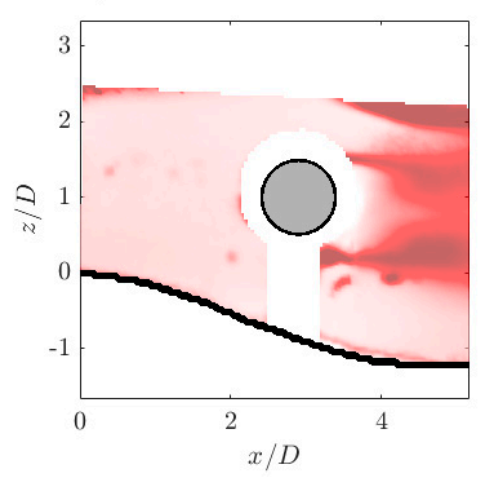

b)

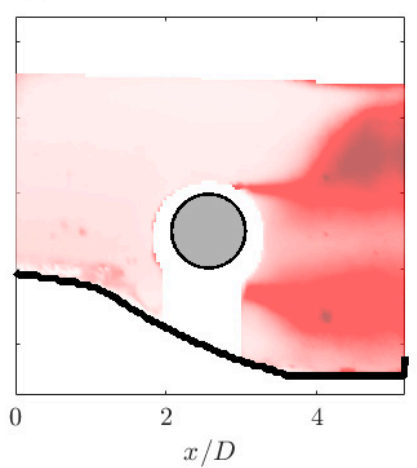

c)

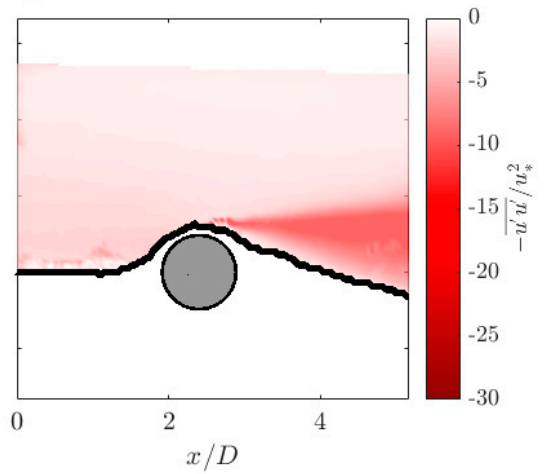

Figure 11. Dimensionless streamwise Reynolds normal stresses on a vertical plane in (a) Run 1, (b) Run 2, (c) Run 3. 
a)

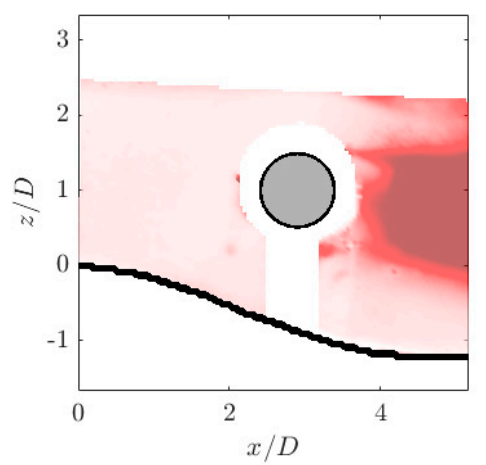

b)

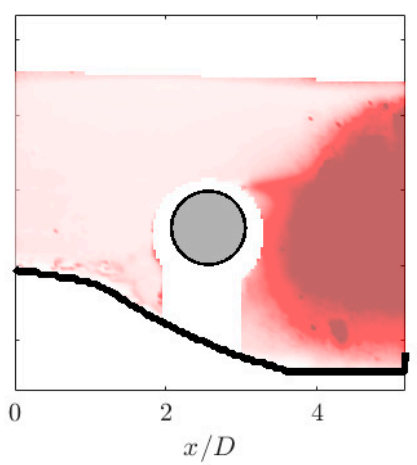

c)

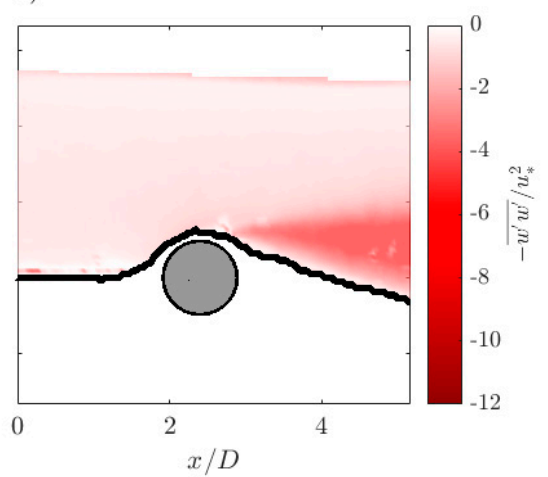

Figure 12. Dimensionless vertical Reynolds normal stresses on a vertical plane in (a) Run 1, (b) Run 2,

(c) Run 3.

In all the experimental runs, upstream to the cylinder, it can be seen that $\sigma_{u u}$ and $\sigma_{w w}$ assume their maximum negative values in the near-bed flow region, and then they increase with $z$. This may be attributed to the fluid mixing that occurs in the presence of bed roughness. At the same time, it can be noted that downstream of the cylinder the intense fluid mixing induced by the presence of the obstacle enhances both the fluctuations $u^{\prime}$ and $w^{\prime}$. The comparison between Run 1 and Run 2 shows that a smaller gap between the cylinder and the bed surface induces the flow area to enlarge with increased magnitude of both $u^{\prime}$ and $w^{\prime}$.

On the other hand, Run 3 shows downstream of the cylinder a decrease of $\sigma_{u u}$ and $\sigma_{w w}$ in the recirculation zone, indicating, also in this case, fluid mixing with a maximum magnitude of $0.08 \mathrm{~m} / \mathrm{s}$ and $0.05 \mathrm{~m} / \mathrm{s}$ for $u^{\prime}$ and $w^{\prime}$, respectively, that are less than those in Run 1 and Run 2, for which $u^{\prime}$ and $w^{\prime}$ are about $0.14 \mathrm{~m} / \mathrm{s}$ and $0.09 \mathrm{~m} / \mathrm{s}$. This leads to a decrease of about $65 \%$ for both $\sigma_{u u}$ and $\sigma_{w w}$.

\subsection{Ensemble-Averaged Turbulence Indicators}

In order to measure the local turbulence level in a flow, the use of the ensemble-averaged turbulence indicator I may represent a useful tool [47]. This parameter can be estimated as follows:

$$
I=\left(\frac{\frac{2}{3} k}{U^{2}}\right)^{0.5}
$$

where $k$ is the turbulent kinetic energy (TKE), expressed as:

$$
k=\frac{1}{2}\left(\overline{u^{\prime} u^{\prime}}+\overline{v^{\prime} v^{\prime}}+\overline{w^{\prime} w^{\prime}}\right),
$$

$v^{\prime}$ being the fluctuations of the spanwise velocity component with respect to its ensemble-averaged value. Since the PIV system allows the measurement of only two velocity components, the term $\overline{v^{\prime} v^{\prime}}$ can be approximated as $0.5\left(\overline{u^{\prime} u^{\prime}}+\overline{w^{\prime} w^{\prime}}\right)[49,50]$. Therefore, the TKE is expressed as:

$$
k=0.75\left(\overline{u^{\prime} u^{\prime}}+\overline{w^{\prime} w^{\prime}}\right) .
$$

The turbulence level is high if $I>0.5$, moderate if $0.1<I<0.5$ and low if $I<0.1$ [51]. Thus, the contours of the ensemble-averaged turbulence indicator for the three experimental runs are shown in Figure 13. It is clear that for Runs 1 and 2 the magnitudes of $I$ are moderate immediately downstream of the cylinder $(I \approx 0.3)$, where the mean velocity is very low and a reverse flow takes place. In the wake region, the fluctuations in the streamwise and vertical directions cause the enhancement of the turbulence level, but it can be still classified as moderate $(I \approx 0.5$ for Run 1 and $I \approx 0.4$ for Run 2 ). However, the area characterized by the enhancement of the turbulence level is greater in Run 2 than 
in Run 1, since in this case it interests the entire flow depth. This can be ascribed to the fact that the increase of the gap between the cylinder and the bed surface (Run 1) causes the formation of two opposite vortices shorter and more compressed than those of Run 2 . This also leads to higher $I$ value in Run 1 than in Run 2. As regards Run 3, the turbulence level reaches a maximum value of about 0.4 in the scour hole downstream of the cylinder and, therefore, it can be classified as a moderate one. Nevertheless, in the rest of the flow domain, the turbulence level is basically low and it decreases as $z$ increases, implying that the roughness effects and the influence of the cylinder diminishes owing to the damping in $u^{\prime}$ and $w^{\prime}$, which is visible also in Figures 11 and 12.

a)

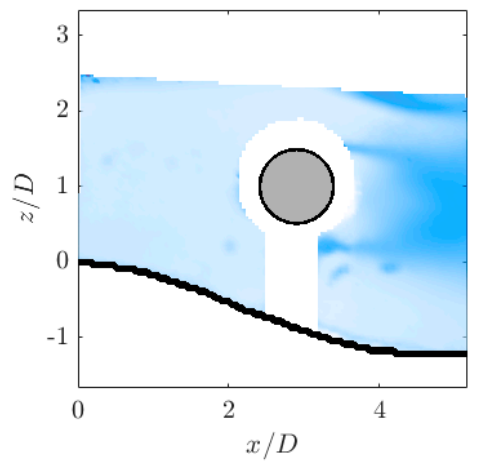

b)

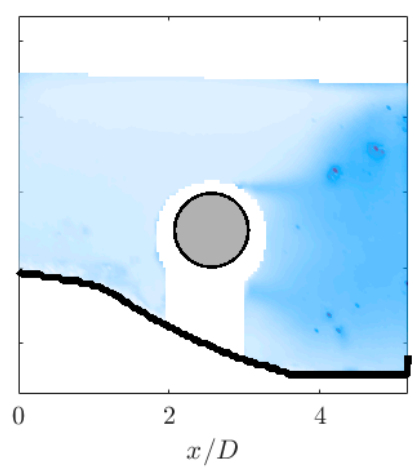

c)

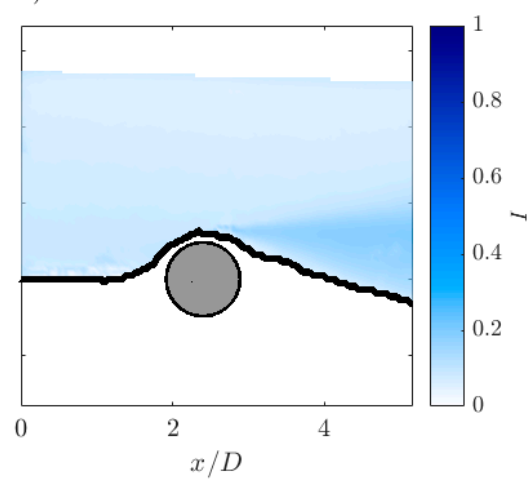

Figure 13. Ensemble-averaged turbulence level on a vertical plane in (a) Run 1, (b) Run 2 and (c) Run 3.

\section{Conclusions}

This study examines the turbulence characteristics at scoured horizontal cylinders in different condition of submergence, in order to deepen the knowledge investigating the flow-structure interactions in the presence of a mobile bed in shallow-water condition. Three experimental runs were performed considering a suspended cylinder, a laid on cylinder and a half-buried cylinder. Specifically, bed scouring occurred in all the runs and the resulting bed configurations were analyzed in order to better comprehend the flow dynamics.

For the first two conditions, at the end of the scouring phase, it was demonstrated that the incoming flow approaches the upstream face of the cylinder and causes flow separation. Thus, the main flow is divided into two flows: one part is oriented towards the bed surface, whereas the other part is oriented towards the free surface. The velocity at the underside of the cylinder is slightly lower than the one at the top side, as observed by Jensen et al. [29] in their experiments. This latter is also responsible for the formation of the scour hole that involves the area upstream to and beneath the cylinder owing to tunnel erosion. This phenomenon is more pronounced when the cylinder is laid on the bed. In the wake zone, for the suspended cylinder a greater amount of flow passes below it. Therefore, this flow tends to expand immediately downstream of the cylinder, limiting the extension of the induced vortex system. The analysis of the vorticity field revealed that in the wake region vorticity assumes positive values in the upper zone and negative values in the lower part, that is with clockwise and counterclockwise rotations, respectively. This is in accordance with the results obtained by Bearman and Zdravkovich [21], Price et al. [24] and others, since it was demonstrated that vortex shedding occurs at gaps higher than $0.3 D$. The strong turbulent mixing process in these areas is highlighted by the Reynolds shear stress distribution, indicating a downward transport of momentum in the downstream direction and an upward transport of momentum in the upstream direction, respectively. To support these observations, the turbulence level was calculated and it was found that fluctuations in the streamwise and vertical directions cause the enhancement of the turbulence level immediately downstream of the obstacle, reaching a value within the range $0.3-0.5$, indicating a moderate turbulence level. 
A different behavior was observed when the cylinder was initially half-buried. Tunnel erosion did not occur and, as a consequence, the obstruction represented by the cylinder created an adverse pressure gradient resulting in the separation of flow lines forming a vortex on the upstream front of the cylinder. Separation of flow also took place at the free-stream side of the cylinder. A reverse roller was formed in the wake region. This was responsible for the local scour downstream of the cylinder. The vorticity pattern showed the presence of the clockwise vortex in the scour hole with a strong mixing process that entrains high-momentum fluid into the recirculation region. It was demonstrated that here the turbulence level can be classified as moderate $(I \approx 0.4)$.

Additional work in the future is required to take into account other variables that may affect the investigated turbulence structures (e.g., cylinder diameter, shape of the pipe, flow discharge, water depth), their development during the scouring process and also other in-depth statistical analyses (such as the third-order statistics to provide a very accurate measure of the TKE dissipation rate [52] or correlation functions to analyze the turbulent coherent structures [53]).

This study represents an advancement in the current understanding of the flow-structure interaction at scoured horizontal cylinders subjected to currents. It was demonstrated that bed changes should be considered in the analysis of the flow field and in the prediction of the forces acting on the cylinder rather than considering a plane boundary, because the effects are very different and depend also on the gap between the cylinder and the bed itself.

Author Contributions: Conceptualization, N.P. and R.G.; Data curation, N.P. and F.C.; Formal analysis, N.P. and F.C.; Methodology, N.P., F.C. and R.G.; Writing-Original Draft Preparation, N.P.; Writing-Review and Editing, N.P., F.C. and R.G.; Supervision, R.G. All authors have read and agreed to the published version of the manuscript.

Funding: This research received no external funding.

Acknowledgments: The authors would like to thank Antonio Leuzzi for his valuable work during the performance of the experimental Runs.

Conflicts of Interest: The authors declare no conflict of interest.

\section{References}

1. Fredsøe, J. Pipeline-seabed interaction. J. Waterw. Port Coast. Ocean Eng. 2016, 142, 03116002. [CrossRef]

2. Azamathulla, H.M.; Yusoff, M.A.M.; Hasan, Z.A. Scour below submerged skewed pipeline. J. Hydrol. 2014, 509, 615-620. [CrossRef]

3. Chiew, Y.M. Prediction of maximum scour depth at submarine pipelines. J. Hydraul. Eng. 1991, 117, $452-466$. [CrossRef]

4. Dey, S.; Singh, N.P. Clear-water scour below underwater pipelines under steady flow. J. Hydraul. Eng. 2008, 134, 588-600. [CrossRef]

5. Chao, J.L.; Hennessy, P.V. Local scour under ocean outfall pipelines. J. Water Pollut. Control Fed. 1972, 44, 1443-1447.

6. Herbich, J.B. Scour around pipelines and other objects. In Offshore Pipeline Design Elements; Marcell Dekker, Inc.: New York, NY, USA, 1981; pp. 43-96.

7. Herbich, J.B. Hydromechanics of submarine pipelines: Design problems. Can. J. Civ. Eng. 1985, 12, 863-874. [CrossRef]

8. Herbich, J.B.; Schiller, R.E., Jr.; Watanabe, R.K.; Dunlap, W.A. Scour around pipelines. In Sea Floor Scour-Design Guidelines for Ocean Founded Structures; Marcell Dekker, Inc.: New York, NY, USA, 1984; pp. 203-210.

9. Kjeldsen, S.P.; Gjorsvik, O.; Bringaker, K.G.; Jacobsen, J. Local scour near offshore pipelines. In Proceedings of the Second International Conference on Port and Ocean Engineering Under Arctic Conditions (POAC), Reykjavík, Iceland, 27-30 August 1973.

10. Bijker, E.W.; Leeuwestein, W. Interaction between pipelines and the seabed under the influence of waves and currents. In Seabed Mechanics; Springer: Dordrecht, The Netherlands, 1984; pp. 235-242.

11. Ibrahim, A.; Nalluri, C. Scour prediction around marine pipelines. In Proceedings of the 5th International Symposium on Offshore Mechanics and Arctic Engineering, Tokyo, Japan, 13 April 1986; pp. 679-684. 
12. Hansen, E.A.; Fredsøe, J.; Mao, Y. Two-dimensional scour below pipelines. In Proceedings of the 5th International Symposium on Offshore Mechanics and Arctic Engineering, Tokyo, Japan, 13-18 April 1985; pp. 670-678.

13. Mao, Y. The Interaction between a Pipeline and an Erodible Bed; Institute of Hydrodynamics and Hydraulic Engineering, Technical University of Denmark: Lyngby, Denmark, 1986; p. 39.

14. Maza, J.A. Introduction to river engineering. In Advanced Course on Water Resources Management; Universitá Italiana per Stranieri: Perugia, Italy, 1987.

15. Moncada-M., A.T.; Aguirre-Pe, J. Scour below pipeline in river crossings. J. Hydraul. Eng. 1999, 125, 953-958. [CrossRef]

16. Chiew, Y.M. Mechanics of local scour around submarine pipelines. J. Hydraul. Eng. 1990, 116, 515-529. [CrossRef]

17. Li, F.; Cheng, L. Numerical model for local scour under offshore pipelines. J. Hydraul. Eng. 1999, 125, 400-406. [CrossRef]

18. Brørs, B. Numerical modeling of flow and scour at pipelines. J. Hydraul. Eng. 1999, 125, 511-523. [CrossRef]

19. Mohr, H.; Draper, S.; Cheng, L.; White, D.J. Predicting the rate of scour beneath subsea pipelines in marine sediments under steady flow conditions. Coast. Eng. 2016, 110, 111-126. [CrossRef]

20. Gao, F.P.; Yang, B.; Wu, Y.X.; Yan, S.M. Steady current induced seabed scour around a vibrating pipeline. Appl. Ocean Res. 2006, 28, 291-298. [CrossRef]

21. Bearman, P.W.; Zdravkovich, M.M. Flow around a circular cylinder near a plane boundary. J. Fluid Mech. 1978, 89, 33-47. [CrossRef]

22. Zdravkovich, M.M. Intermittent flow separation from flat plate induced by a nearby circular cylinder. In Proceedings of the International Symposium on Flow Visualization, Bochum, Germany, 9-12 September 1981; pp. 219-224.

23. Lei, C.; Cheng, L.; Kavanagh, K. Re-examination of the effect of a plane boundary on force and vortex shedding of a circular cylinder. J. Wind Eng. Ind. Aerodyn. 1999, 80, 263-286. [CrossRef]

24. Price, S.J.; Sumner, D.; Smith, J.G.; Leong, K.; Paidoussis, M.P. Flow visualization around a circular cylinder near to a plane wall. J. Fluids Struct. 2002, 6, 175-191. [CrossRef]

25. Hatipoglu, F.; Avci, I. Flow around a partly buried cylinder in a steady current. Ocean Eng. 2003, 30, $239-249$. [CrossRef]

26. Akoz, M.S.; Sahin, B.; Akilli, H. Flow characteristic of the horizontal cylinder placed on the plane boundary. Flow Meas. Instrum. 2010, 21, 476-487. [CrossRef]

27. Arslan, T.; Malavasi, S.; Pettersen, B.; Andersson, H.I. Turbulent flow around a semi-submerged rectangular cylinder. J. Offshore Mech. Arct. Eng. 2013, 135, 041801. [CrossRef]

28. Malavasi, S.; Guadagnini, A. Interactions between a rectangular cylinder and a free-surface flow. J. Fluids Struct. 2007, 23, 1137-1148. [CrossRef]

29. Jensen, B.L.; Sumer, B.M.; Jensen, H.R.; Fredsøe, J. Flow around and forces on a pipeline near a scoured bed in steady current. J. Offshore Mech. Arct. Eng. 1990, 112, 206-213. [CrossRef]

30. Smith, H.D.; Foster, D.L. Modeling of flow around a cylinder over a scoured bed. J. Waterw. Port Coast. Ocean Eng. 2005, 131, 14-24. [CrossRef]

31. Nezu, I.; Nakagawa, H. Turbulence in Open-Channel Flows; Balkema Publishers/IAHR-monograph: Rotterdam, The Netherlands, 1993; p. 293.

32. Neill, C.R. Mean-velocity criterion for scour of coarse uniform bed material. In Proceedings of the International Association of Hydraulic Research 12th Congress, Fort Collins, CO, USA, 11-14 September 1967; Volume 3, pp. 46-54.

33. Da Silva, A.F.; Yalin, M.S. Fluvial Processes, 2nd ed.; IAHR-monograph: Delft, The Netherlands, $2017 ;$ p. 266.

34. Padhi, E.; Penna, N.; Dey, S.; Gaudio, R. Hydrodynamics of water-worked and screeded gravel beds: A comparative study. Phys. Fluids 2018, 30, 085105. [CrossRef]

35. Balakumar, B.J.; Orlicz, G.C.; Tomkins, C.D.; Prestridge, K.P. Simultaneous particle-image velocimetry-planar laser-induced fluorescence measurements of Richtmyer-Meshkov instability growth in a gas curtain with and without reshock. Phys. Fluids 2008, 20, 124103. [CrossRef]

36. Balakumar, B.J.; Prestridge, K.P.; Orlicz, G.; Balasubramanian, S.; Tomkins, C. High resolution experimental measurements of Richtmyer-Meshkov turbulence in fluid layers after reshock using simultaneous PIV-PLIF. AIP Conf. Proc. 2009, 1195, 659-662. [CrossRef] 
37. Gonçalves, J.A.; Henriques, R. UAV photogrammetry for topographic monitoring of coastal areas. ISPRS J. Photogramm. Remote Sens. 2015, 104, 101-111. [CrossRef]

38. Fortunato, G.; Funari, M.F.; Lonetti, P. Survey and seismic vulnerability assessment of the Baptistery of San Giovanni in Tumba (Italy). J. Cult. Herit. 2017, 26, 64-78. [CrossRef]

39. Bertin, S.; Friedrich, H.; Delmas, P.; Chan, E.; Gimel'farb, G. Dem quality assessment with a 3d printed gravel bed applied to stereo photogrammetry. Photogramm. Rec. 2014, 29, 241-264. [CrossRef]

40. Penna, N.; D'Alessandro, F.; Gaudio, R.; Tomasicchio, G.R. Three-dimensional analysis of local scouring induced by a rotating ship propeller. Ocean Eng. 2019, 188. [CrossRef]

41. Sumer, B.M.; Fredsøe, J. The Mechanics of Scour in the Marine Environment; Advanced Series on Ocean Engineering; World Scientific: Singapore, 2002; Volume 17, p. 552.

42. Sumer, B.M.; Truelsen, C.; Sichmann, T.; Fredsøe, J. Onset of scour below pipelines and self-burial. Coast. Eng. 2001, 42, 313-335. [CrossRef]

43. Sumer, B.M.; Fredsøe, J. Hydrodynamics around Cylindrical Structures; Advanced Series on Ocean Engineering; World Scientific: Singapore, 2006; Volume 26, p. 548.

44. Grass, A.J.; Raven, P.W.J.; Stuart, R.J.; Bray, J.A. The influence of boundary layer velocity gradients and bed proximity on vortex shedding from free spanning pipelines. J. Energy Resour. Technol. 1984, 106, 70-78. [CrossRef]

45. Raven, P.W.J.; Stuart, R.J.; Bray, J.A.; Littlejohns, P.S. Full-scale dynamic testing of submarine pipeline spans. In Proceedings of the 17th Annual Offshore Technology Conference, Houston, TX, USA, 6-9 May 1985; paper No. 5005. pp. 395-404.

46. Roshko, A. Experiments on the flow past a circular cylinder at very high Reynolds number. J. Fluid Mech. 1961, 10, 345-356. [CrossRef]

47. Padhi, E.; Penna, N.; Dey, S.; Gaudio, R. Near-bed turbulence structures in water-worked and screeded gravel-bed flows. Phys. Fluids 2019, 31, 045107. [CrossRef]

48. Adrian, R.J. Structure of turbulent boundary layers. In Coherent Flow Structures at Earth's Surface; Venditti, J.G., Best, J.L., Church, M., Hardy, R.J., Eds.; John Wiley \& Sons: Chichester, UK, 2013; pp. 17-24.

49. Antonia, R.A.; Luxton, R.E. The response of a turbulent boundary layer to a step change in surface roughness. Part 2. Rough-to-smooth. J. Fluid Mech. 1972, 53, 737-757. [CrossRef]

50. Padhi, E.; Penna, N.; Dey, S.; Gaudio, R. Spatially averaged dissipation rate in flows over water-worked and screeded gravel beds. Phys. Fluids 2018, 30, 125106. [CrossRef]

51. Russo, F.; Basse, N.T. Scaling of turbulence intensity for low-speed flow in smooth pipes. Flow Meas. D Instrum. 2016, 52, 101-114. [CrossRef]

52. Coscarella, F.; Servidio, S.; Ferraro, D.; Carbone, V.; Gaudio, R. Turbulent energy dissipation rate in a tilting flume with a highly rough bed. Phys. Fluids 2017, 29, 085101. [CrossRef]

53. Caroppi, G.; Västilä, K.; Järvelä, J.; Rowiński, P.M.; Giugni, M. Turbulence at water-vegetation interface in open channel flow: Experiments with natural-like plants. Adv. Water Resour. 2019, 127, 180-191. [CrossRef] 